ojs.uv.es/index.php/qdfed

Rebut: 02.06.2020. Acceptat: I6.07.2020

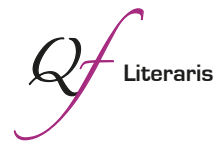

Per a citar aquest article: Zagron Engelhard, Bernardo. 2020. "Alegoría de un polisistema en la obra Paparazzi, de Matei Visniec”. Quaderns de Filologia: Estudis Literaris XXV: I57-I69.

doi: $10.7203 /$ qdfed.25.I9000

\title{
Alegoría de un polisistema en la obra Paparazzi, de Matei Visniec
}

\section{Allegory of a polysystem in Matéi Visniec's play Paparazzi}

\author{
BERNARDO ZAGRON ENGELHARD \\ Universitat de València \\ bzagrone@gmail.com
}

Resumen: Este artículo analizará la manera en que Matei Visniec, a través de su obra de teatro Paparazzi, da a ver la estructura silogística de su obra, así como la del polisistema de deformaciones que nos rodea y asedia. Trataremos de describir los mecanismos mediante los cuales el autor rumano apunta a la necesidad del sabotaje. En efecto, a través de una puesta en abismo del proceso de creación de contenidos de los medios de comunicación de masas, Paparazzi pone en evidencia en forma de alegoría teatral aquello mismo a lo que alude Asensi, esto es, el hecho de que los discursos que modelizan nuestra percepción del mundo son una representación alterada de la realidad que necesita ser saboteada.

Palabras clave: Sabotaje; Teatro; Alegoría; Polisistema de deformaciones; Medios de comunicación de masas.

\begin{abstract}
This article will analyze the way in which Matei Visniec, through his play Paparazzi, shows the syllogistic structure of his own play, as well as that of the polysystem of deformations that surrounds and assails us. We will try to describe the mechanisms by which the Romanian author points out the need for sabotage. In fact, In fact, by a mise en abyme of the process of creating mass media content, Paparazzi brings out in the form of a theatrical allegory to which Asensi alludes, that is, the fact that the discourses that model our perception of the world are an altered representation of reality that needs to be sabotaged.
\end{abstract}

Keywords: Sabotage; Theater; Allegory; Polysystem of deformations; Mass media. 


\section{Introducción}

En los tiempos que corren, afirmar que vivimos asediados por representaciones alteradas de la realidad, o lo que es lo mismo, afirmar, como afirma uno de los personajes de Matei Visniec, que hoy en día "todo es texto, todo es literatura" (2009: I4), es casi una obviedad. También lo es, hasta cierto punto, señalar que las distintas "lámparas deformantes" que conforman nuestro modo de percibir el mundo (TV, radio, internet, literatura, y un largo etcétera²) ejercen sobre nosotros una "acción modelizadora", entendiendo esta como:

la acción consistente en crear sujetos (cuerpos, gestos, acciones, discursos, subjetividades) que se representan, perciben y conciben el mundo y a sí mismos según modelos previamente codificados, esto es, ideológicos, cuya finalidad es la práctica de una política normativa y obligatoria, y cuya estrategia consiste en presentarse como "naturales" (Pérez, 20II: I5).

Lo que no lo es tanto, y este es, digámoslo ya, el objeto central de la crítica como sabotaje y del presente artículo, es detenerse a analizar los mecanismos mediante los cuales tal acción se ejerce y se hace efectiva. Y es evidente que no basta con saber que tal modelización tiene lugar, para que uno quede liberado de sus efectos. De hecho, no parece necesaria una gran perspicacia sociológica para entrever el hecho de que la sociedad neoliberal del hiperconsumo y del entretenimiento parece haber resuelto lo que Aldous Huxley denominaba "el problema de la felicidad, es decir, el problema de conseguir que la gente ame su servidumbre" (2003: I6) Se necesita por tanto, si no se quiere ser sujeto pasivo de esa modelización, algo más que un mero saber que existe. Sobre este punto volveremos más adelante.

Antes, cabe recordar que son muchos los autores que han puesto de manifiesto que en la actual sociedad del espectáculo3n, nuestra percepción del mundo está sumamente mediatizada y alejada de la realidad. Esa observación tiene que ver con el lugar central que ocupa la representación en la construcción de nuestra realidad psíquica, es decir, en nuestra percepción de lo que el mundo es. Pero no hay que olvidar que dichas representaciones, a fin de

\footnotetext{
I Todas las citas pertenecientes a ediciones francesas han sido traducidas por mí, en aras de facilitar la lectura.

${ }^{2}$ Todo aquello que Manuel Asensi, de acuerdo con la teoría desarrollada en la Universidad de Tel-Aviv por el Culture Research Group, denomina "polisistema de deformaciones" (Pérez, 20II). ${ }_{3}^{3}$ Para la noción de sociedad del espectáculo, véase: Debord, G. (I992). La société du spectacle. París: Gallimard
} 
cuentas, no son sino ejemplos, analogías que son presentadas como si fuesen la realidad, pero que no lo son. Y a lo que ese como si remite es a la "confusión de la realidad semiótica y la realidad fenoménica" (Pérez, 20II: 48), cuya condición de posibilidad es el empleo de estructuras silogísticas que permiten al sujeto transitar de lo particular a lo universal. Va de sí, pues, que detenerse a analizar la manera en que las "lámparas deformantes" modelizan nuestra subjetividad, implica detenerse en dichas estructuras, pues son las que permiten que un ejemplo sea tomado como modelo, y que el sujeto actúe en el mundo de acuerdo con sus premisas.

Así, si afirmamos que, más que actuar, el sujeto es actuado, y si ese ser actuado tiene que ver con el hecho de que hoy en día "todo es texto, todo es literatura", entonces cualquier intento de acción autónoma, o al menos, cualquier intento de tomar conciencia de la manera en que uno es actuado, pasa, como afirma uno de los personajes de Matei Visniec por efectuar una "semiótica de la textualidad urbana", y por observar cómo "todos esos textos (nos) manipulan"4 (Visniec, 2009: 15).

En este sentido, la obra de Visniec ofrece algunas claves sobre cómo mantener una cierta libertad frente a los aparatos ideológicos. De hecho, él mismo admite que el propósito de su escritura no es otro que el de "resistir, mantenerse lúcido", y no dejarse manipular "ni por el régimen totalitario, ni por el «mundo libre»" (9m53s, Visniec, 20I4). Y es que tras huir de la dictadura de Ceausescu para recaer en París, el autor descubre que el denominado "mundo libre" esconde en realidad otras formas de manipulación frente a las que se antoja indispensable resistirs. Ese afán de resistencia se hace visible a través de una obra novelesca, poética y teatral, que no oculta su parentesco con los autores del absurdo, pero que lo dota de una fuerte dimensión crítica. En este sentido, la obra de teatro Paparazzi, ou la chronique d'un lever de soleil avorté (1996) ${ }^{6}$,cobra especial interés, pues se presenta como la alegoría de un "polisistema de deformaciones" cuyo silogismo es puesto ante los ojos del

\footnotetext{
${ }_{4}^{4}$ En esta obra, Visniec efectúa una mise en abyme de su proceso de creación literaria, y aprovecha para atribuirse una tarea en tanto autor comprometido. Dicha tarea no es otra que la de efectuar esa "semiótica de la textualidad urbana".

${ }^{5}$ A este respecto, resulta reveladora la obra Occident Express (Matei Visniec, 2009), en la cual el autor da a ver la fuerte idealización de la que el mundo occidental era objeto en los países comunistas.

${ }^{6}$ La obra fue presentada por primera vez ante el público en I997 en el Festival de Avignon, bajo la dirección de Christian Auger (Compagnie Pli Urgent), y ha sido puesta en escena en otras dos ocasiones, tanto en Francia como en Rumanía.
} 
lector, de manera que este se ve invitado a buscar el silogismo allí donde no es tan visible. La obra se sitúa en una ciudad indeterminada de occidente en la que suceden muchas de las cosas que, de facto, suceden en las ciudades de occidente. Algunos personajes (los de la jet-set) se entregan al más puro hedonismo, otros tratan a toda costa de alcanzar el modus vivendi de los primeros, y otros tantos se quedan fuera de la carrera. En medio de este paisaje, los medios de comunicación y sus principales actores ejercen su papel de mediadores, seleccionando las parcelas de realidad que darán a ver a los espectadores, y ejerciendo así su acción modelizadora. Hasta aquí, nada parece insólito. No obstante, la acción tiene como telón de fondo una implosión solar que debería suponer el fin del mundo, y es este elemento fatídico el que dota a la acción de un carácter marcadamente absurdo, que permite la risa del espectador, pero que en segunda instancia invita a la reflexión.

El presente artículo analizará, pues, uno de los aspectos de la obra que a nuestro parecer ponen en evidencia, por un lado, la presencia de lámparas deformantes, y por otro lado, los efectos performativos que estas ejercen sobre los sujetos. Así, veremos en primer lugar la forma en que Paparazzi, en su modo retórico, se presenta como una obra saboteadora. En segundo lugar veremos en qué sentido se puede decir que Paparazzi es la puesta en abismo de un polisistema de deformaciones. Por último analizaremos la manera en que la obra da a ver los efectos performativos de dicho polisistema, a través de un modelo de abundancia que es seguido por numerosos personajes, y cuyo falso silogismo es puesto en evidencia por el dramaturgo.

\section{Paparazzi y la cuestión de la referencialidad}

Si algo se desprende claramente de esta introducción, es sin lugar a duda el hecho de que la capacidad modelizante de un texto depende en gran medida de su grado de referencialidad. Dicho de otro modo, un texto cuyo modelo de mundo mantiene marcadas similitudes con el mundo empírico en el que se desenvuelve el lector, es un texto que tiende a ocultar su carácter silogístico (esto es, en términos de Asensi, un texto tético), y por tanto, su carácter ideológico. En cambio, un texto que da a ver su estructura silogística pone de relieve que su realidad semiótica no es coincidente con la realidad empírica (atético $)^{7}$, y pone por tanto en crisis la posibilidad de que ambas sean con-

\footnotetext{
7 Para más detalle sobre esta distinción entre textos téticos y textos atéticos, véase Pérez, M. A. (20II). Crítica y Sabotaje. Barcelona: Anthropos, p.52-53.
} 
fundidas. Si bien esta distinción es hecha por Asensi con fines meramente pragmáticos, y si bien existe, como veremos, una amplia escala de grises entre ambos polos, se antoja esencial situar la obra de Visniec con respecto a estos, para analizar la forma en que el dramaturgo apela al lector.

En este sentido, el elemento que desencadena la acción teatral en Papara$z z i$ es clave: se trata de un desastre ${ }^{8}$, una implosión solar que, según ciertos indicios, se estaría produciendo mientras transcurre la acción, y que debería suponer el fin del mundo. Y a pesar de que la obra mantiene en todo momento la incertidumbre en cuanto al carácter real o ficticio de este fenómeno en el plano de la acción, dicha implosión no deja de ser un detalle crucial, por cuanto tiñe la obra de una fatalidad que la acerca a la tragedia clásica. Y es que, tanto por parte de los personajes, como a ojos del lector, aparecen contempladas en todo momento dos posibilidades. Por una parte, parece que el fenómeno cósmico está teniendo lugar realmente, pero por otra parte se sugiere la posibilidad de que se trate de un invento de los medios de comunicación de masas (que desempeñan un papel esencial en la obra). En cualquier caso, esa incertidumbre actúa como un agravante del fatum, en la medida en que obliga a los personajes a actuar sin certeza alguna, de la misma manera que el lector o espectador se ve obligado a interpretar lo que ve o lee, con la tensión que provoca ese no saber.

Pero además de lo anterior, la propia naturaleza del elemento fatídico puede dar lugar a dos posibilidades de interpretación, cuyos efectos son distantes en cuanto al grado de referencialidad que confieren a la obra. Y es que si, por una parte, la presencia de un elemento apocalíptico aleja la acción del mundo que rodea al receptor, por otra, el hecho de que dicho elemento sea precisamente un fenómeno cuyo advenimiento ha sido demostrado por la ciencia, otorga a la obra un marcado carácter realista. Dicho de otro modo, la posibilidad del apocalipsis, por lo que para el lector tiene de improbable o lejano, es el elemento que hace que emerja con claridad la estructura silogística del texto. De ahí que, a pesar de contar con elementos marcadamente realistas, la obra sea capaz de suscitar la risa de un lector al que le resulta difícil olvidar el carácter ficticio de aquello que está leyendo. Sin embargo, la implosión solar puede ser interpretada también como un surgimiento implacable de lo real en el plano de la ficción, pues hace referencia a un fenómeno cósmico existente (supernova), y del que se sabe que, en el mejor de los casos, supondrá el final de la aventura humana. De hecho, la fidelidad de la descripción dada

\footnotetext{
${ }^{8}$ En el sentido literal del término, que significa no astro (lat. des-astrum).
} 
en la obra por el profesor Pandolfi, con respecto a la definición científica del fenómeno, llama la atención, y puede incluso generar una cierta angustia:

(...) es una caída de la materia sobre sí misma, una especie de increíble contracción... Una estrella que sufre una implosión es como un agujero negro que absorbe repentinamente su propia energía (Visniec, 1996: 33).

De este modo, al poner al lector frente a la conciencia de su propia finitud, y al hacerlo mediante un elemento tan ineluctable, se logra que la acción oscile entre dos polos: al dar a ver su estructura silogística, se hace posible la risa, pero se trata de una risa que se vuelve nerviosa, cuando uno advierte que aquello que la provoca no está tan alejado del mundo que le rodea. De hecho, a esto último contribuyen unos cuantos elementos de la obra, como el hecho de que la acción se sitúe en una ciudad occidental ${ }^{9}$ no especificada, o el de que ninguno de los personajes tenga nombre propio. Ambos detalles, entre otros, otorgan a la ficción una vocación de universalidad que invita a la generalización del sentido. De este modo, Paparazzi introduce en su modo retórico un doble discurso que le dota de una dimensión alegórica, y que invita al lector a interrogar al texto en todo momento. Una invitación, por tanto, a ser ese lector desobediente que requiere la crítica como sabotaje.

\section{Paparazzi, alegoría de un polisistema de deformaciones}

Así, aunque la acción transcurra con un posible fin del mundo como telón de fondo, y aunque ello nos haga presuponer que la obra debe ser leída como algo alejado de lo real, son varios los elementos que sugieren que esa lejanía no es tal. Entre todos ellos emerge, por su centralidad en la trama teatral, la referencia directa a lo que antes hemos denominado "lámparas deformantes", que al ser tratada mediante la mise en abyme actúa como un espejo que revela al observador otro punto de vista sobre su propio entorno. Así, Paparazzi es una lámpara deformante en la que se dan a ver otras lámparas deformantes, de tal manera que se puede considerar la obra de Visniec como la alegoría de un polisistema de deformaciones a cuyo sabotaje se nos está incitando, por el mero hecho de mostrarnos sus propiedades deformadoras, así como los efectos performativos que de estas se derivan.

\footnotetext{
9 A lo largo de este artículo entenderemos Occidente, no tanto en su sentido geográfico, como en el sentido del modelo económico neoliberal al que hace referencia.
} 
A este respecto, la primera escena de la obra es explícita. En ella aparece Paparazzo I (en adelante, PI) en una habitación alta con ventanas tras las cuales tiene colocadas varias cámaras "apuntando hacia abajo", en una disposición escénica que recuerda a la prisión panóptica pensada por Jérémy Bentham, de la que Michel Foucault se servirá metafóricamente en Surveiller et Punir (1975) para describir determinados sistemas de control y condicionamiento social.

El primer signo auditivo impuesto por el autor es el tono de un teléfono móvil que "Paparazzo I descuelga" inmediatamente (Visniec, I996: 9). Del otro lado de la línea se escucha la voz de su Jefe, que le interroga acerca de lo que ve a través de las ventanas, y de aquello que hace la gente a la que está espiando. El lector/espectador descubre así, a través de este diálogo, lo que sucede fuera del escenario: se trata de una Mujer Famosa (en adelante MF) que organiza una fiesta que está a punto de comenzar, y en la que "tout le beau monde ne tardera pas à se pointer" ${ }^{\circ}$.

En resumidas cuentas, lo primero a lo que apunta la acción, es al hecho de que la representación (teatral) pone en el abismo otra representación (la narración que Pi le hace a su jefe), que debe dar lugar a una tercera representación (la del medio de comunicación que publicará el reportaje). De hecho, la descripción verbal hecha por Pi para su jefe sugiere que la representación que se dará a ver en el reportaje mostrará una versión alterada de la realidad, ávida de impacto, y que contrasta con lo que el espectador puede ver de manera directa en otras escenas de la obra. En primer lugar porque de su conversación se desprende que hay ciertos ejes temáticos en los que Pi debe centrar su atención. En segundo lugar, porque la mirada de PI, más allá de esos ejes temáticos, no es una mirada autónoma. Al contrario, se trata de una mirada teledirigida por un jefe que no aparece nunca físicamente en escena, pero que no obstante interroga, guía, y dirige constantemente, y que en definitiva rastrea, filtra, y corta, aquello que de la realidad (esa realidad que no ve, y que de hecho no le interesa) vale la pena mostrar. No es necesario apuntar que ese valer la pena responde a criterios económicos ligados a las ventas que el reportaje es susceptible de generar.

\footnotetext{
ro Hemos optado aquí por mantener la expresión francesa "tout le beau monde", puesto que contiene un doble sentido que remite a la vez a una dimensión estética, y a un determinado estatus social (elevado). Una propuesta de traducción podría ser toda esa gente guapa de la alta sociedad no tardará en plantarse aquí".
} 
Así pues, las imágenes de abundancia de la MF, o aún los contenidos de carácter sexual o violento son algunos de los temas que interesan especialmente a Pi y a su jefe, lo cual no deja de remitir al lector a un determinado tipo de contenido mediático reconocible en su entorno (el show business). Por otra parte, algo similar ocurre con Paparazzo 2 (P2), cuyo rol está no obstante más orientado a cubrir las páginas de sucesos. Una vez más, los hechos no son mostrados de forma directa, sino que son puestos en abismo a través de las conversaciones entre P2 y su Jefe, siempre en la sombra. No obstante nos centraremos principalmente en observar cómo, en su obra, Visniec pone en abismo representaciones alteradas de la realidad, en las cuales la abundancia y el hiperconsumo son presentados como modelos, y cómo a su vez dichas representaciones ejercen un poder performativo sobre sus receptores, que se ven incitados a actuar de acuerdo a sus premisas.

En este sentido, tal como ya se ha apuntado, el personaje de la MF, y todo lo que de su modus vivendi nos es mostrado a través de PI, posee una importante carga simbólica, por cuanto remite de forma directa al mundo de la prensa rosa y a los modelos que en ella imperan. De hecho, dicho personaje corresponde exactamente a la definición de Zygmunt Bauman, que menciona a la persona famosa como una persona "conocida por ser muy conocida" (Bauman, 20Io: 69). Y efectivamente, así le es presentada al lector: como una persona pudiente, pero sin oficio ni beneficio. Son varios los signos, por tanto, que remiten a un modo de vida ocioso, plagado de excesos, y que se desarrolla en un entorno social privilegiado, una suerte de Jet Set. Es de reseñar, eso sí, la forma en que todos estos elementos son dotados de atractivo por el punto de vista subjetivo de Paparazzo i, así como por el de su jefe, que dirige su mirada. A este respecto, la primera escena no deja lugar a equívocos: desde su escondite, Pi nos habla de la MF, que está fuera de escena, diciendo de ella que ha "dormido todo el día", que tiene "un masajista", y dos "gorilas" entre los cuales hay un "profesor de gimnasia" con el que hace deporte "en traje de baño" dentro de la "piscina", y que además , organiza una "fiesta" con "al menos doscientas personas". Sin obviar que toda esa "gente hermosa" será atendida por "camareros" (Visniec, I996: 9-I0). En esta misma línea, son muchos los signos que muestran una imagen idealizada de la abundancia que rodea a la MF y a su fiesta. En este sentido, se puede decir que la abundancia es (re) presentada como modelo a seguir en el plano de la ficción, y como veremos más adelante, esa (re)presentación ejerce un poder performativo sobre los personajes receptores. Un ejemplo casi caricaturesco lo podemos encontrar en el intercambio entre Pi y su jefe, en la escena 7: 
PAPARAZZO I: (...) Si viese las botellas de champán Cordon Bleu flotando en la piscina... Y el caviar que han tirado dentro... Anda! Hay un tipo que acaba de subirse a la mesa.

LA VOZ DEL CHEF: ¿Quién es?

PAPARAZZO ı: No lo sé, jefe. Ha llenado los platos y ahora está caminando sobre los platos. Pero no lo conozco. (Visniec, I996: 26)

En definitiva, resulta bastante evidente que lo que se está poniendo ante los ojos del lector es un modelo que idealiza el exceso. Sin embargo, como ya hemos indicado, nos ocupa analizar la forma en que Visniec nos invita al sabotaje de los modelos que nos rodean y de los silogismos que nos incitan a una acción determinada y no del todo autónoma. En este sentido, lo importante de lo anteriormente descrito es que se trata de una representación. En ningún momento el lector/espectador tiene un acceso directo a la MF. Al contrario, se trata de una visión mediatizada, parcelada, de una realidad que por tanto deviene en una alteración, efecto luminoso provocado por una de esas lámparas deformantes antes mencionadas, pero que no obstante ejerce su poder performativo. Y esta última afirmación es puesta en evidencia, en el seno de la estructura teatral, mediante dos mecanismos principales: el primero de ellos consiste en dar a ver al lector diversos ejemplos de sujetos/personajes que, de forma bastante absurda, dado el contexto apocalíptico en que transcurre la acción, siguen ciegamente tratando de alcanzar esa abundancia cuyo anhelo les ha sido manifiestamente inoculado. El segundo mecanismo tiene que ver con la construcción de una sintaxis en la que, de forma progresiva, se va mostrando, esta vez de forma directa, la realidad de quien parece ser la Mujer Famosa. Realidad, por cierto, muy distinta a la que captaban las cámaras de PI.

En cuanto al primer punto, si bien se podrían dar numerosos ejemplos, señalaremos uno que resulta bastante representativo de la tendencia de los sujetos a seguir las premisas de la sociedad de consumo y su exaltación del exceso y la abundancia. Nos referimos concretamente al Jefe, del que ya hemos hablado, y cuya voz es escuchada en cinco ocasiones a lo largo de la obra. Dicha voz alterna las llamadas telefónicas entre Pi y P2, y sus cinco surgimientos marcan una cadencia regular, del mismo modo que de forma regular, el autor recuerda al inicio de cada escena que "el tiempo pasa", y que el desastre está, presumiblemente, cada vez más cerca. Sin embargo, esto último no obsta para que en todo momento el Jefe persiga un único objetivo: dirigir la mirada de sus trabajadores, de manera que estos le aporten un material que sea susceptible de generar los máximos beneficios para su empresa. Todo ello, 
recordémoslo, sucede obviando el hecho de que el mundo en el que transcurre la acción está amenazado por un final inminente, lo cual dota la acción de un carácter marcadamente absurdo. Así pues, aunque dado el contexto apocalíptico, resulta absurdo el interés que el jefe muestra en las imágenes de una locomotora descontrolada impactando contra una estación de tren (Esc.6) , o aún en las de un político siendo agredido en plena calle (Esc.Io), se puede decir que aún hay, en estos momentos de la obra, un argumento en defensa del jefe y del objetivo que persigue: y es que ni el lector ni los personajes saben a ciencia cierta si el sol, efectivamente, ha sufrido una implosión, o si por el contrario, se trata de una "manipulación (...) una movida publicitaria, o algo así” (Visniec, I996: 23). En este sentido, aunque el afán del jefe pueda parecer un objetivo poco noble frente a la dimensión de la tragedia, no deja de existir esa posibilidad a la que, en algún momento, y con un entusiasmo perceptible, hace referencia Pr: "Esta explosión cósmica de la que hablaba... Si salimos de esta... y si publicamos esto..." (Visniec, I996: 28). No obstante, la progresión de la obra hace aparecer con cada vez mayor certeza, el carácter disparatado de tal empresa, llevándolo a su punto más extremo cuando, a la hora en que tenía que salir el sol, tanto el jefe como Pi constatan que, en efecto, el sol no sale, resultando así ridículas las palabras que el jefe pronuncia ante la fatal evidencia:

LA VOZ DEL JEFE: (...) si el puto sol sale de todos modos, tómale una foto al momento. Quiero algunas fotos bonitas del maldito sol, si es que se sale, ¿entiendes? Como salga, voy a lanzar una edición especial con el puto sol en primera plana. ¿Me entiendes? (Visniec, I996: 55).

Se ve claro aquí que su negativa a aceptar lo que a ojos del lector ya parece evidente, hace que esa carrera desenfrenada en busca del beneficio económico aparezca como un sinsentido.

En esta misma línea, se pueden mencionar otros ejemplos, como el del dueño de un restaurante que insiste en cobrarle la cuenta a un cliente, a pesar de que este le recuerde repetidas veces que es el fin del mundo (Esc.II), o aún el ejemplo de un vagabundo que en un monólogo inicial rompe el cuarto muro para increpar a unos transeúntes invisibles por su ceguera consumis$\operatorname{ta}^{\mathrm{II}}$, y que termina, en una escena bastante simbólica, aceptando dos latas de

\footnotetext{
II "Demasiado Coco / Demasiado Lancôme/ Demasiado Cacharel /Demasiado Yves Saint-Laurent/ Demasiado Givenchy Demasiadas Rochas/ Demasiado Christian Dior/ Demasiada mierda..." (Visniec, I996: I5)
} 
Coca-Cola, de una máquina dispensadora viviente con la cual mantiene una conversación. Aunque no podamos detenernos aquí en todos estos ejemplos, es de señalar el hecho de que los efectos performativos que ejerce el modelo de abundancia y de consumo mencionado, se hacen visibles en diversos niveles de lo que podríamos llamar la "escala social" de la obra.

Queda patente, pues, que Visniec pone en evidencia ante el lector el poder modelizante de los medios de comunicación, así como el hecho de que tal poder se ejerce a partir de visiones parceladas de la realidad. Dicho de otro modo, hemos visto que Paparazzi, en su modo retórico, da a ver la estructura silogística usada por los medios de comunicación en las representaciones de la realidad que transmiten. Hemos visto también que, como toda representación, estas suponen igualmente una alteración de la realidad, pero que ello no obsta para que los sujetos las tomen como modelo. Nos queda, por tanto, un último aspecto que hay que analizar. Pues, si bien Visniec introduce en el plano microtextual indicios que, como hemos visto, dan a ver el carácter absurdo de seguir determinadas consignas, también emergen algunos elementos en la sintaxis de la obra que resultan relevantes, y que sugieren al lector que lo que le es presentado como modelo está preso en un falso silogismo. Nos referimos en concreto al personaje de la Mujer Famosa.

Como ya se ha visto, dicho personaje nos es presentado indirectamente al inicio de la obra, como representativo de una clase social pudiente, y por tanto, a priori, más susceptible que otros de lograr la felicidad que el modelo consumista promete a través del consumo y del exceso. Sin embargo, existen diversos indicios que ponen en crisis la posibilidad de tal logro. Además, dichos indicios, que ahora veremos, apuntan de forma clara a la contradicción que en otra parte señala Zygmunt Bauman, esto es, al hecho de que "la sociedad de consumo justifica su existencia con la promesa de satisfacer los derechos humanos como ninguna otra sociedad pasada ha conseguido hacerlo" (...) pero, en realidad "esa promesa de satisfacción solo puede ser seductora en la medida en que el deseo permanece insatisfecho" (Bauman, 2006: ro9).

En efecto, el devenir del personaje de la MF en la obra pone de manifiesto la insatisfacción permanente de la que es objeto. Así, tras la descripción inicial que nos brinda PI, la MF vuelve a ser mencionada por el fotógrafo en la escena 7. En esta ocasión, se nos dice que "no deja de beber y de llorar como una loca" (Visniec, I996: 27), síntoma evidente de un malestar que contrasta con la promesa de felicidad que su situación parecía prometer al inicio. Poco después, en la escena 8, las acotaciones nos hablan de una Mujer Descalza, vestida con un "elegantísimo traje de noche" (Visniec, I996: 29), lo cual hace 
pensar que se trata de la MF. Sin embargo, su aspecto físico ha sufrido un deterioro, su vestido está "sucio y arrugado", "parece cansada" y "da la sensación de que está vagando por la ciudad". Pero aunque estos son indicios de que ni el exceso, ni el lujo, ni el hecho de pertenecer a la Jet Set, logran aportarle plenitud, el dramaturgo organiza un encuentro al final de la obra que resulta esencial para poner en evidencia el vacío existencial que habita a la MF. Así, el ejemplo más flagrante del malestar que padece se nos muestra en la escena II, a través su encuentro con el hombre para el cual el nacimiento fue una caída, cuyo discurso remite al lector a la obra de Cioran, De l'inconvenient d'être né (I973). Dicho personaje cuenta así las razones de su malestar existencial a la MF que escucha entre lágrimas:

EL HOMBRE PARA EL QUE EL NACIMIENTO FUE UNA CAÍDA: Sí. Porque antes, antes, había... En la carne de mi madre, mi vida... era la paz. Perfección... Ubicuidad... Pertenecer a un mundo homogéneo y simple, donde el espacio y el tiempo eran reemplazados por las leyes más sutiles de la organicidad. Porque había, en esta carne de mi madre que rodeaba mi propia carne, una gran reserva de calma... Era, ya ves, confianza, armonía...(...)

(...)

¡Pero no soy sólo yo! Todos nosotros, entiendes, todos hemos vivido este momento de armonía, pero nuestra tragedia es que todos hemos olvidado que... (Visniec, 1996: 46-47)

Las lágrimas de la mujer ante este discurso muestran claramente que el modelo de abundancia, que al inicio de la obra era presentado como un modelo especialmente atractivo y como un ideal a alcanzar, no resuelve este malestar existencial que el hombre, a través de su discurso, muestra como inexorable y universal, y ante el cual la mujer no puede sino llorar desconsoladamente. Sobra decir que en este punto de la realidad las cámaras de Paparazzo i ya no se detienen, y que todo interés, tanto suyo, como de su jefe, ha decaído por completo, lo cual no hace sino poner en evidencia el silogismo que opera en el citado polisistema de deformaciones. En definitiva, al obviar una parte de la realidad, el Jefe y Pi crean la realidad que dicen describir, y de esa realidad deformada se desprenden una serie de actitudes a adoptar en el mundo, que como se ha hecho patente, parten de un falso silogismo (entimema). Es por ello que resulta a la vez cómico y patético el hecho de que incluso el Jefe y Pi sigan persiguiendo hasta el final el ideal que ellos mismos contribuyen a crear. En definitiva, parece que tampoco ellos ven, o que no quieren ver, o que ven pero deciden ignorar la cara oculta de la moneda. 


\section{Bibliografía}

Asensi Pérez, Manuel. 20II. Crítica y Sabotaje. Anthropos.

Bauman, Zygmunt. 20I0. La Vida líquida. Traducción de Albino Santos Mosquera. Paidós.

Cioran, Emil. I973. De l'inconvénient d'être né (vol. 480). Éditions Gallimard.

Foucault, Michel. I975. Surveiller et Punir. Naissance de la prison (vol. 2004). Gallimard. https://doi.org/I0.39I7/sh.colle.2013.02.0047

Huxley, Aldous. 2003. Un mundo feliz. Madrid: Ed. De Bolsillo.

Visniec, Matei. 2009. Occident Express. Ecritures Théâtrales Grand Sud-Ouest.

Visniec, Matéi. I996. Paparazzi, ou la chronique d'un lever de soleil avorté. Actes Sud-Papiers.

Visniec, Matéi. 2009. La Vieille Dame Qui Fabrique 37 Cocktails Molotov par Jour. Ecritures Théâtrales Grand Sud-Ouest.

Visniec, Matéi. 20I4. Mateï Visniec auteur et journaliste RFI. https://www.youtube. com/watch?v=YwHpW5ru_nw 
